\title{
Inhaled nitric oxide reduces ischemia-reperfusion injury in rat lungs from non-heart-beating donors
}

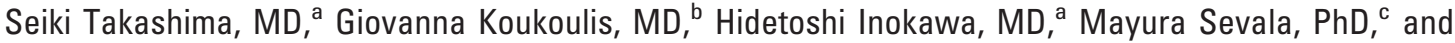

Thomas M. Egan, MD, MSc ${ }^{\mathrm{C}}$

From the Department of Cancer and Thoracic Surgery (Surgery II), ${ }^{\text {a }}$ Okayama University Graduate School of Medicine and Dentistry, Okayama, Japan; the Department of Cardiothoracic Surgery, ${ }^{\mathrm{b}}$ University of Pavia, Pavia, Italy; and the Division of Cardiothoracic Surgery, Department of Surgery, ${ }^{\mathrm{c}}$ University of North Carolina, Chapel Hill, NC.

Supported by National Institutes of Health grant R01 HL63159-01A2.

Received for publication Oct 27, 2005; revisions received Jan 12, 2006; accepted for publication Feb 21, 2006.

Address for reprints: Thomas M. Egan, MD, Division of Cardiothoracic Surgery, University of North Carolina at Chapel Hill, CB \#7065; 3040 Burnett Womack Building, Chapel Hill, NC 27599-7065 (Email: 1txtme@med.unc.edu).

J Thorac Cardiovasc Surg 2006;132:132-9

$0022-5223 / \$ 32.00$

Copyright (๑) 2006 by The American Association for Thoracic Surgery

doi:10.1016/j.jtcvs.2006.02.032
Objective: If lungs could be retrieved from non-heart-beating donors, the critical shortage of lungs for transplantation could be alleviated. However, lungs subjected to warm ischemia develop edema when reperfused. We hypothesized that ventilation of rat lungs from non-heart-beating donors with nitric oxide during the period of warm ischemia alone, with reperfusion, or both might reduce ischemia-reperfusion injury.

Methods: An isolated perfused rat lung model measured the filtration coefficient and accumulation of lung water by the wet/dry weight ratio. Donor rats were euthanized, and then lungs were retrieved immediately after death or 2 or 3 hours postmortem. Lungs retrieved postmortem were either not ventilated or ventilated with $100 \%$ oxygen alone or $40 \mathrm{ppm}$ nitric oxide in oxygen. In the circuit, lungs were ventilated with alveolar gas with or without $40 \mathrm{ppm}$ nitric oxide.

Results: Nitric oxide administration to the non-heart-beating donor or in the perfusion circuit reduced filtration coefficient and wet/dry weight ratio. Lungs retrieved 2 hours postmortem ventilated with nitric oxide or treated with nitric oxide on reperfusion had filtration coefficients and wet/dry weight ratios similar to those of lungs retrieved immediately after death. Nitric oxide was most beneficial when administered both during warm ischemia and at reperfusion in lungs retrieved 3 hours postmortem. Nitric oxide administration in the circuit was associated with increased lung levels of lung cyclic guanosine monophosphate, determined by enzyme-linked immunosorbent assay.

Conclusions: Administration of nitric oxide to non-heart-beating donors during warm ischemia and with reperfusion might facilitate transplantation of lungs from non-heartbeating donors by reducing ischemia-reperfusion injury and capillary leak.

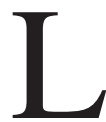

ung transplantation is an effective therapy to palliate patients with end-stage lung disease, but widespread use is severely limited by an inadequate supply of suitable lungs from conventional organ donors. If lungs could be retrieved from non-heart-beating donors (NHBDs), the critical shortage of lungs for transplantation could be alleviated. ${ }^{1}$ However, this strategy might be limited by ischemia-reperfusion injury (IRI) due to unavoidable warm ischemic time in the deceased donor.

The critical shortage of donor lungs has prompted our laboratory to investigate the use of NHBDs in experimental models of lung transplantation. ${ }^{1-3}$ We have used an isolated perfused rat lung model (IPRLM) to measure changes in filtration coefficient (Kfc) in the Starling equation to assess the early phase of IRI in rat lungs obtained from NHBDs. ${ }^{4}$ Lungs retrieved 2 hours postmortem had substantially increased capillary leak, which was manifested by increased Kfc and wet/dry weight ratios (W/D).

Nitric oxide (NO) donors can reduce IRI, presumably due to endothelial synthesis of $\mathrm{NO}$, a potent vasodilator that inhibits neutrophil adhesion, platelet aggrega- 


$$
\begin{aligned}
& \text { Abbreviations and Acronyms } \\
& \begin{aligned}
\text { cAMP } & =\text { cyclic adenasine monophosphate } \\
\text { cGMP } & =\text { guanosine } 3^{\prime}, 5^{\prime} \text { monophosphate } \\
\text { IPRLM } & =\text { isolated perfused rat lung model } \\
\text { IRI } & =\text { ischemia-reperfusion injury } \\
\text { Kfc } & =\text { filtration coefficient } \\
\text { NHBD } & =\text { non-heart-beating donor } \\
\text { NO } & =\text { nitric oxide } \\
\text { NO-D } & =\text { inhaled NO during the ischemic interval } \\
& \text { alone } \\
\text { NO-D+R = inhaled NO during both the ischemic } & \text { interval and reperfusion } \\
\text { NO-R }= & \text { inhaled NO during reperfusion alone } \\
\text { NTG } & =\text { nitroglycerin } \\
\text { PEEP } & =\text { positive end-expiratory pressure } \\
\text { Ppv } & =\text { pulmonary venous pressure } \\
\text { W/D } & =\text { wet/dry weight ratio }
\end{aligned}
\end{aligned}
$$

tion, and endothelial cytokine-induced activation. ${ }^{5}$ These effects are mediated by NO stimulation of guanylate cyclase, converting guanosine triphosphate to guanosine $3^{\prime}, 5^{\prime}$ monophosphate (cGMP). Levels of endogenous NO and cGMP are quickly reduced during IRI. ${ }^{6}$ Inhaled NO reduced $\mathrm{Kfc}$ and neutrophil activation in isolated blood-perfused rat lungs. ${ }^{7}$ Reperfusion of lungs retrieved from NHBDs with the NO donor nitroglycerin (NTG) reduced Kfc and W/D ratios, allowed for Kfc assessment of nonventilated cadaver lungs retrieved 3 hours postmortem, and was associated with an increase in lung tissue levels of cGMP. ${ }^{8}$ The airway provides an avenue for delivery of oxygen and potentially for delivery of other therapeutic agents that might reduce subsequent IRI in lungs from NHBDs. Therefore, the present study was designed to assess the effect of NO administration to lungs after circulatory arrest, during reperfusion, or both in the IPRLM.

\section{Materials and Methods \\ IPRLM}

The specific details of our IPRLM have been outlined previously. ${ }^{4}$ Briefly, male Sprague-Dawley rats weighing 250 to $450 \mathrm{~g}$ were anesthetized with intraperitoneal pentobarbital sodium $(35 \mathrm{mg} / \mathrm{kg}$; Abbott Laboratories, Chicago, Ill). Heparin (600 units) (ElkinsSinn, Cherry Hill, NJ) was injected intrahepatically, and the trachea was cannulated with p60 tubing. The rat was then euthanized with a lethal intrahepatic injection of pentobarbital sodium (120 $\mathrm{mg} / \mathrm{kg}$ ). The heart-lung block was left in situ to simulate the NHBD clinical scenario as closely as possible. At intervals after death, the lungs were removed and reperfused in the IPRLM. Circuit perfusate was Earle's balanced salt solution containing 2.4 mmol $\mathrm{CaCL}_{2} \cdot 2 \mathrm{H}_{2} \mathrm{O}, 0.4 \mathrm{mmol} \mathrm{MgSO}_{4}$ (anhydrous), $5.4 \mathrm{mmol}$ $\mathrm{KCl}, 116 \mathrm{mmol} \mathrm{NaCl}, 0.88 \mathrm{mmol} \mathrm{NaH}_{2} \mathrm{PO}_{4}$ (anhydrous), 5.5 mmol D-glucose, and $0.3 \mathrm{mmol}$ phenol red containing $0.21 \%$ $\mathrm{NaHCO}_{3}$ and $4 \%$ bovine serum albumin (Sigma Chemical, St Louis, Mo). Rat lungs were ventilated in the IPRLM with alveolar gas $\left(5 \% \mathrm{CO}_{2}, 20 \% \mathrm{O}_{2}\right.$, balance $\left.\mathrm{N}_{2}\right)$ at 60 breaths/min, a tidal volume of $3 \mathrm{~mL}$, and positive end-expiratory pressure (PEEP) of 2 $\mathrm{cm} \mathrm{H}_{2} \mathrm{O}$. When $\mathrm{NO}$ was administered in the IPRLM circuit (inhaled NO during reperfusion alone [NO-R] and inhaled NO during both the ischemic interval and reperfusion $[\mathrm{NO}-\mathrm{D}+\mathrm{R}]$ ), the lungs were ventilated with $40 \%$ flow from a tank containing $100 \mathrm{ppm}$ $\mathrm{NO}$ in $\mathrm{N}_{2}$ and $60 \%$ flow from a custom gas mixture $\left(8 \% \mathrm{CO}_{2}, 33 \%\right.$ $\mathrm{O}_{2}$, balance $\mathrm{N}_{2}$ ) to render a gas composition of $5 \% \mathrm{CO}_{2}, 20 \% \mathrm{O}_{2}$, balance $\mathrm{N}_{2}$ with $40 \mathrm{ppm}$ NO. The concentration of $\mathrm{NO}$ was monitored continuously just proximal to the endotracheal tube by using chemiluminescence analyzers (Freedom 5000; Scott Instruments, Exton, Pa). Perfusate temperature was maintained at between $35^{\circ} \mathrm{C}$ and $38.5^{\circ} \mathrm{C}$, and perfusate $\mathrm{pH}$ was continuously monitored with a $\mathrm{pH}$ probe (Accumet; Fisher Scientific, Pittsburgh, Pa) in the venous reservoir. The $\mathrm{pH}$ was maintained near 7.40 by adding diluted $\mathrm{HCl}$ or $\mathrm{NaHCO}_{3}$ as necessary.

\section{Specific Protocol}

Sixty pairs of lungs were divided into 10 groups ( $\mathrm{n}=6$ per group). Two groups served as controls, with lungs retrieved immediately after euthanasia and reperfused within 5 minutes of death, ventilated in the IPRLM with alveolar gas or ventilated in the IPRLM with 40 ppm NO, $5 \% \mathrm{CO}_{2}$, and $20 \% \mathrm{O}_{2}$ (0h NO-R). Four groups had lungs retrieved 2 hours postmortem: nonventilated control lungs ( $2 \mathrm{~h} \mathrm{NV}$ ), lungs from nonventilated NHBDs ventilated in the IPRLM with NO (2h NO-R), lungs ventilated in the NHBD with NO (2h NO-D) and then evaluated in the IPRLM without NO, and lungs ventilated both after euthanasia and in the IPRLM (2h NO-D $+R$ ). In earlier studies lungs retrieved from cadavers ventilated for 2 hours with oxygen had similar Kfc values and W/D ratios as lungs retrieved 2 hours postmortem from nonventilated animals, ${ }^{4,8}$ and therefore studies of this group were not repeated. For NHBDs, NO was administered into the inspiratory limb of the respirator circuit as a mixture of $100 \mathrm{ppm}$ in pure nitrogen (at $40 \%$ total flow) with $100 \% \mathrm{O}_{2}$ at $60 \%$ flow for a concentration of $60 \%$ $\mathrm{O}_{2}$ plus $40 \mathrm{ppm} \mathrm{NO}$ at 60 breaths/min, a tidal volume of $3 \mathrm{~mL}$, and a PEEP of $2 \mathrm{~cm} \mathrm{H}_{2} \mathrm{O}$. Four groups had lungs retrieved 3 hours postmortem: control lungs were ventilated in the NHBD with $100 \% \mathrm{O}_{2}$ (3h O2-vent) nonventilated NHBDs ventilated in the IPRLM with NO (3h NO-R), lungs ventilated in the NHBD with NO (3h NO-D) and then evaluated in the IPRLM without NO, and lungs ventilated both after euthanasia and in the IPRLM (3h NO-D $+R$ ). Nonventilated lungs retrieved 180 minutes postmortem and not treated with NO could not be included because of consistent development of pulmonary edema $(n=6)$. All animals received humane care in accordance with the "Guide for the Care and Use of Laboratory Animals" (National Institutes of Health publication no. 85-23, revised 1985).

\section{Pulmonary Hemodynamics and Airway Pressure}

Pressure transducers recorded pulmonary arterial (Ppa), venous $(\mathrm{Ppv})$ and airway (Paw) pressure continuously. All pressure measurements and changes in weight gain were recorded by using the Lab View SCXI Pressure Weight Acquisition System (National Instruments, Austin, Tex) on a Gateway E-3400 computer. Pulmonary arterial resistance (Rpa) and venous resistance (Rpv) were calculated according to the following formulas: 


$$
R p a=(P p a-P p c) / Q \text { and } R p v=(P p c-P p v / Q,
$$

where $\mathrm{Q}$ is flow in milliliters per minute.

\section{Determination of Kfc}

Pulmonary capillary pressure $(\mathrm{Ppc})$ measurement and calculation of $\mathrm{Kfc}$ has been outlined in detail elsewhere. ${ }^{4}$ Briefly, Kfc is calculated by $\log$ transformation of $\Delta$ w between minutes 6 and 15 by using linear regression of the log-10 weight changes per minute extrapolated back to time zero after increasing the height of the venous reservoir. The $\Delta \mathrm{w} / \Delta \mathrm{t}$ between minutes 6 and 15 represents increased transvascular fluid flux secondary to increased capillary permeability. Kfc is normalized by using baseline wet lung weight and expressed as milliliters per minute per centimeter $\mathrm{H}_{2} \mathrm{O}$ per $100 \mathrm{~g}$ of lung tissue.

\section{W/D Ratios}

At the completion of the experiment, the upper lobe of the right lung was excised and immediately weighed. It was then dried in a $60^{\circ} \mathrm{C}$ oven for 48 hours and reweighed, and the ratio was calculated. The remaining lung tissue was cut into multiple pieces, snap-frozen in liquid nitrogen, and stored at $-80^{\circ} \mathrm{C}$ until subsequent extraction and analysis.

\section{High-performance Liquid Chromatography}

Tissue samples retrieved from the right lung underwent ice-cold $0.6 \mathrm{~N}$ perchloric acid extraction and measurement of adenine nucleotides by HPLC using a Beckman System Gold apparatus (Beckman Instruments, Fullerton, Calif), as previously described. ${ }^{8}$ Values were corrected for lung water content by expressing results as micromoles per gram of dry weight.

\section{cGMP Determinations}

cGMP was analyzed by using the Biotrak enzyme immunoassay (EIA) system from Amersham Biosciences Corp (Code RPN 226) (Buckinghamshire, UK) after extraction, as described previously. ${ }^{8}$ Data were corrected for water content by calculating the W/D ratio from a frozen portion of each sample, and results were expressed as femtomoles of cGMP per milligram of dry weight.

\section{Statistics}

Statistical analysis was performed by using analysis of variance with the Tukey's post-hoc test for multiple comparisons for groups of lungs studied 120 and 180 minutes postmortem or an unpaired $t$ test for lungs studied immediately after death (with and without NO ventilation in the circuit). Separate analyses of variance (ANOVAs) with the Tukey post-hoc test for multiple comparisons were performed across time points for the same conditions (with or without NO) by using Statistica (Tulsa, Okla). Calculation of means, standard errors, and logistic regression were performed with Excel 2000 (Microsoft, Redmond, Wash). All values are reported as the mean \pm standard error of the mean. Differences were considered significant when $P<.05$.

\section{Results}

Kfc

Differences in the Kfc are shown in Figure 1. Lungs retrieved immediately after death had normal Kfc values $(0.3$

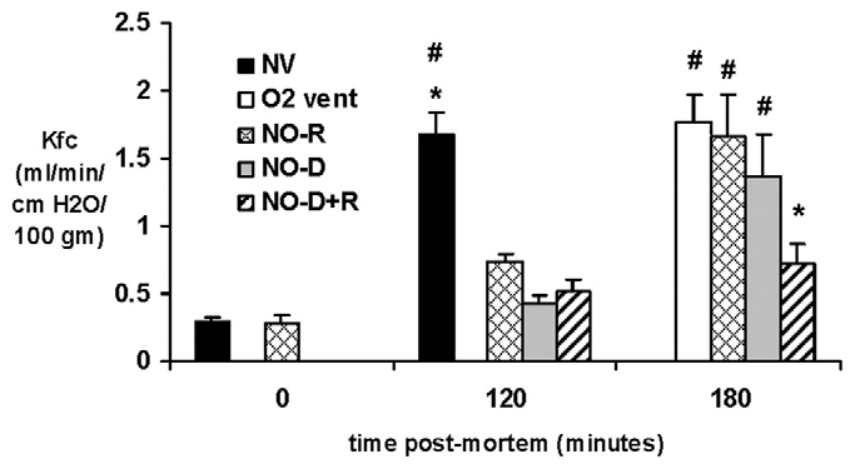

Figure 1. Filtration coefficient $(K f c)$ values increased with increasing postmortem ischemic time, but the increase was diminished by ventilation with $40 \mathrm{ppm}$ nitric oxide (NO) during the ischemic interval (D) or with reperfusion (R). The effect of NO ventilation during both the ischemic interval and with reperfusion $(D+R)$ resulted in substantial attenuation of Kfc values in lungs studied 3 hours after death. Although Kfc values increased with postmortem ischemic time, when NO was administered both during ischemia and with reperfusion $(D+R)$, the increase was not statistically significant. Mean \pm standard error of the mean, $n=6$ per group. ${ }^{*} \boldsymbol{P}<.05$ compared with other groups at the same postmortem time interval. \#P $<.05$ compared with appropriate time 0 group.

$\mathrm{mL} / \mathrm{min} / \mathrm{cm} \mathrm{H}_{2} \mathrm{O} / 100 \mathrm{~g}$ lung weight), irrespective of whether they were ventilated in the IPRLM circuit with NO. In lungs retrieved 2 hours postmortem, Kfc was markedly increased in nonventilated nontreated lungs (control). Inhaled NO during reperfusion (NO-R) or during the ischemic interval alone (NO-D) decreased the Kfc value significantly, as did the combination of $\mathrm{NO}$ administration during ischemia and with reperfusion $(\mathrm{NO}-\mathrm{D}+\mathrm{R})$. Although the $\mathrm{Kfc}$ value was modestly increased in NO-treated lungs retrieved 2 hours postmortem compared with that seen in lungs assessed immediately postmortem, these differences did not reach statistical significance. In lungs retrieved 3 hours postmortem, the Kfc value was not measurable in nonventilated lungs because of pulmonary edema. The Kfc value could be measured in $\mathrm{O}_{2}$-ventilated cadavers studied 3 hours postmortem and was markedly elevated. Inhaled NO during both periods of warm ischemia (NO-D) or reperfusion (NO-R) decreased the $\mathrm{Kfc}$ value compared with $\mathrm{O}_{2}$ ventilation of cadavers alone, and the Kfc value was significantly reduced when NO was administered both during ischemia and with reperfusion $(\mathrm{NOD}+\mathrm{R})$.

\section{W/D Ratio}

Differences in W/D ratios are shown in Figure 2. Lungs retrieved immediately after death had normal W/D rations (5.8), irrespective of whether they were ventilated with NO. In lungs retrieved 2 hours postmortem, W/D ratios were 


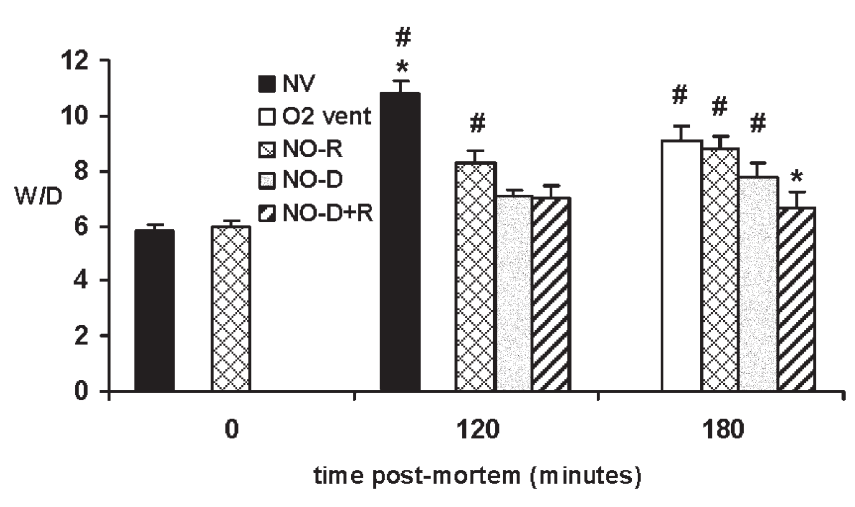

Figure 2. Wet/dry weight ratio (W/D) reflects edema fluid accumulation and showed a pattern similar to that seen with the filtration coefficient (Kfc). Administration of $40 \mathrm{ppm}$ nitric oxide (NO) during the ischemic interval (D) or with reperfusion (R) reduced the amount of edema in lungs retrieved from NHBDs. Mean \pm standard error of the mean, $n=6$ per group. ${ }^{*} P<.05$ compared with other groups at the same postmortem time interval. \#P<.05 compared with appropriate time 0 group.

markedly elevated in the nonventilated group not treated with NO. Inhaled NO during reperfusion or during ischemia had similar effects on W/D ratios and Kfc values. The effect of $\mathrm{NO}$ administration on W/D ratios was most marked when it was administered during ischemia and reperfusion (NO$\mathrm{D}+\mathrm{R}$ ). In lungs retrieved 3 hours postmortem, W/D ratios were markedly increased in the absence of NO treatment. Inhaled NO during either warm ischemia or reperfusion decreased W/D ratios, with a significant reduction observed when $\mathrm{NO}$ was administered both during warm ischemia and with reperfusion (NO-D $+\mathrm{R}, P<.05)$ compared with $\mathrm{O}_{2}$ ventilation alone.

The relationship between Kfc values and W/D ratios is depicted in Figure 3. There was an excellent correlation between Kfc values and W/D ratios, supporting the hypothesis that the Kfc value was associated with capillary leak leading to pulmonary edema.

\section{Hemodynamics}

Hemodynamic data are shown in Table 1 . The changes in $\mathrm{Kfc}$ values and W/D ratios cannot be explained by minimal differences in vascular pressures or resistance.

\section{Adenine Nucleotides}

Lung levels of adenine nucleotides are shown in Table 2. Adenosine triphosphate (ATP) and adenosine monophosphate plus adenosine diphosphate plus adenosine triphosphate (TAN) levels were significantly reduced in some groups of lungs retrieved 2 or 3 hours postmortem compared with lungs retrieved immediately. The benefit of NO treatment on Kfc values and W/D ratios cannot be attributed to improved tissue levels of adenine nucleotides.
A

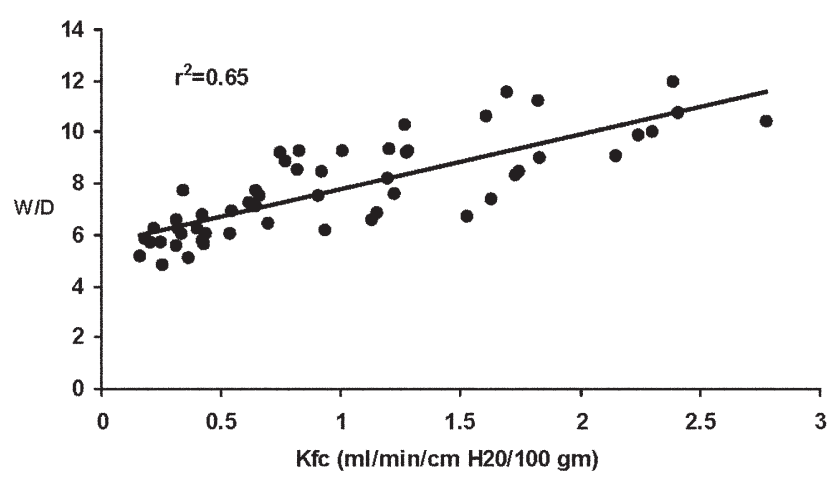

B

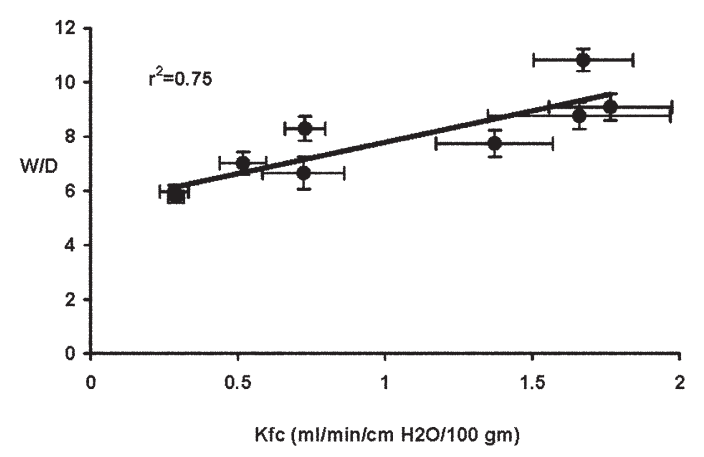

Figure 3. Relationship between filtration coefficient $(K f c)$ and wet/dry weight ratio (W/D) A, for all experiments (n $=60, P<$ $.00001)$ and $B$, for the individual groups $(P<.002)$.

\section{cGMP}

Figure 4 shows that cGMP levels in lung tissue were higher in lungs ventilated with $\mathrm{NO}$ in the circuit (NO-R or NO$\mathrm{D}+\mathrm{R}$ ). If $\mathrm{NO}$ was administered to the cadaver but not continued with reperfusion (NO-D), lung cGMP levels were slightly but not significantly elevated, implying that the effect of NO ventilation on lung tissue cGMP levels was transient and not sustained after reperfusion for 30 minutes in the absence of NO ventilation. cGMP levels increased in nontreated lungs with increasing postmortem ischemic time. By 3 hours, this difference, although modest, was significant when compared with levels found in lungs retrieved immediately after death.

\section{Discussion}

If lungs could be retrieved from NHBDs hours after death and successfully transplanted, the critical shortage of lungs for transplantation could be alleviated. Experimental evidence supporting the potential use of lungs from NHBDs has been reviewed. ${ }^{9}$ Although cessation of the circulation 
Table 1. Hemodynamic data

\begin{tabular}{|c|c|c|c|c|c|}
\hline $\begin{array}{l}\text { Time postmortem } \\
(\mathrm{min})\end{array}$ & NO & PA (mm Hg) & PV (mm Hg) & $\begin{array}{c}\text { RA (mm Hg/ } \\
\left.\mathrm{mL} / \mathrm{min}^{-1}\right)\end{array}$ & $\begin{array}{c}\mathrm{RV}(\mathrm{mm} \mathrm{Hg} / \\
\left.\mathrm{mL} / \mathrm{min}^{1}\right)\end{array}$ \\
\hline \multirow[t]{2}{*}{$0 \min$} & None & $6.82 \pm 0.26$ & $0.50 \pm 0.12$ & $0.4 \pm 0.06$ & $0.28 \pm 0.04$ \\
\hline & $\mathrm{R}$ & $6.97 \pm 0.53$ & $0.56 \pm 0.04$ & $0.38 \pm 0.02$ & $0.35 \pm 0.03$ \\
\hline \multirow[t]{4}{*}{$120 \mathrm{~min}$} & Nonventilated & $7.22 \pm 0.58$ & $0.45 \pm 0.15$ & $0.43 \pm 0.04$ & $0.32 \pm 0.05$ \\
\hline & $\mathrm{D}$ & $12.63 \pm 1.0^{*} \dagger$ & $0.32 \pm 0.05 t$ & $0.38 \pm 0.04$ & $0.48 \pm 0.04$ \\
\hline & $\mathrm{R}$ & $8.41 \pm 0.64$ & $0.55 \pm 0.13$ & $0.51 \pm 0.03 \dagger$ & $0.47 \pm 0.09$ \\
\hline & $\mathrm{D}+\mathrm{R}$ & $8.57 \pm 0.67$ & $0.44 \pm 0.07$ & $0.44 \pm 0.05$ & $0.46 \pm 0.03$ \\
\hline \multirow[t]{4}{*}{$180 \mathrm{~min}$} & $\mathrm{O}_{2}$ ventilated & $9.79 \pm 0.51 \dagger$ & $0.29 \pm 0.07$ & $0.47 \pm 0.04$ & $0.34 \pm 0.02$ \\
\hline & $D^{2}$ & $9.14 \pm 0.52$ & $0.38 \pm 0.05$ & $0.31 \pm 0.03 \dagger$ & $0.34 \pm 0.05$ \\
\hline & $\mathrm{R}$ & $7.76 \pm 0.45$ & $0.42 \pm 0.03$ & $0.33 \pm 0.03$ & $0.37 \pm 0.05$ \\
\hline & $D+R$ & $8.2 \pm 0.48$ & $0.41 \pm 0.06 \dagger$ & $0.42 \pm 0.05$ & $0.41 \pm 0.06$ \\
\hline
\end{tabular}

All values are reported as mean \pm standard error of the mean. $N O$, Nitric oxide; $P A$, pulmonary artery pressure; $P V$, pulmonary venous pressure; $R A$, pulmonary arterial resistance; $R V$, pulmonary venous resistance; $R$, recipient; $D$, donor. $* P<.05$ compared with others at the same postmortem ischemic time. $\dagger P<.05$ compared with time zero with or without NO (by analysis of variance with Tukey's correction).

with cardiac arrest promptly leads to irreversible ischemia and cell death in other organs, this process might be delayed in the lung because the lung parenchyma does not rely on vascular perfusion for cellular respiration. Rather, it would appear that cellular respiration occurs directly across the alveolar wall, and gas exchange processes are entirely passive. Pulmonary epithelial tissue retrieved from morgue specimens is routinely successfully cultured, supporting the hypothesis that some human lung tissue remains viable for several hours after circulatory arrest and death.

Despite improved preservation techniques, IRI to the transplanted lung remains a significant problem in the early postoperative period. In the lung, IRI is manifest as an orchestrated series of events, ${ }^{10}$ some occurring very early after reperfusion and others occurring much later, perhaps related to alterations in gene transcription and protein expression.

The IPRLM is a very sensitive measure of pulmonary capillary function and has been used extensively to character- ize the early response of the pulmonary microcirculation to ischemia, followed by reperfusion or hypoxiareoxygenation. ${ }^{11,12}$ We have used this model to characterize the time course of early changes in permeability with reperfusion in rat lungs left in situ for intervals after circulatory arrest and death. ${ }^{4}$ By leaving lungs in situ after the animal was euthanized, instead of the alternative of harvesting, immediate perfusion, and then making the lung ischemic, our model more closely resembles the clinical scenario of the NHBD. We have chosen to administer heparin in donors before death so that we can evaluate the effect of ischemia alone on capillary function. In the clinical scenario of lung retrieval from NHBDs, it might be possible to administer heparin in potential donors after death by means of intracardiac injection and a brief period of cardiopulmonary resuscitation to distribute heparin to the pulmonary microcirculation.

The asanguineous nature of this model is a particular strength because it demonstrates the effects of reperfusion

Table 2. Adenine nucleotides

\begin{tabular}{|c|c|c|c|c|c|}
\hline $\begin{array}{l}\text { Time } \\
\text { postmortem }\end{array}$ & NO & AMP & ADP & ATP & TAN \\
\hline \multirow[t]{2}{*}{$0 \min$} & None & $1.07 \pm 0.32$ & $1.97 \pm 0.23$ & $3.05 \pm 0.07^{*}$ & $6.1 \pm 0.28^{*}$ \\
\hline & $\mathrm{R}$ & $0.86 \pm 0.3$ & $1.48 \pm 0.39$ & $2.4 \pm 0.28$ & $4.75 \pm 0.54$ \\
\hline \multirow[t]{4}{*}{$120 \mathrm{~min}$} & Nonventilated & $0.7 \pm 0.34$ & $1.22 \pm 0.68$ & $1.93 \pm 0.34 \dagger$ & $3.86 \pm 0.81 \dagger$ \\
\hline & $\mathrm{D}$ & $0.99 \pm 0.58$ & $1.10 \pm 0.27$ & $1.73 \pm 0.27$ & $3.83 \pm 0.61$ \\
\hline & $\mathrm{R}$ & $0.74 \pm 0.26$ & $1.22 \pm 0.14$ & $1.58 \pm 0.41$ & $3.56 \pm 0.46$ \\
\hline & $\mathrm{D}+\mathrm{R}$ & $0.43 \pm 0.83$ & $1.37 \pm 0.29$ & $1.45 \pm 0.68$ & $3.25 \pm 0.39$ \\
\hline \multirow[t]{4}{*}{$180 \min$} & $\mathrm{O}_{2}$ ventilated & $0.72 \pm 0.33$ & $1.53 \pm 0.30$ & $1.97 \pm 0.32 \dagger$ & $4.24 \pm 0.61$ \\
\hline & $\mathrm{D}$ & $0.54 \pm 0.21$ & $0.46 \pm 0.05$ & $1.43 \pm 0.19$ & $2.45 \pm 0.07 \dagger$ \\
\hline & $\mathrm{R}$ & $0.41 \pm 0.15$ & $0.72 \pm 0.13$ & $1.91 \pm 0.24$ & $3.05 \pm 0.41$ \\
\hline & $D+R$ & $0.48 \pm 0.14$ & $0.97 \pm 0.38$ & $1.38 \pm 0.15$ & $2.85 \pm 0.41 \dagger$ \\
\hline
\end{tabular}

All values are presented as mean \pm standard error of the mean in micromoles per gram of dry weight. NO, Nitric oxide; $A M P$, adenosine monophosphate; $A D P$, adenosine diphosphate; $A T P$, adenosine triphosphate; TAN, AMP + ADP +ATP. $* P<.05$ compared with others at the same postmortem ischemic time (unpaired $t$ test). $\dagger P<.05$ compared with time zero with or without NO (by analysis of variance with Tukey's correction). 


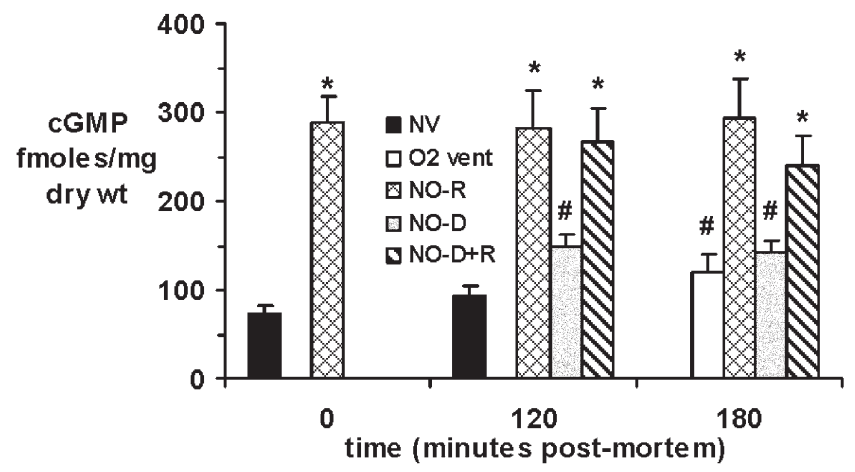

Figure 4. Lung tissue guanosine $3^{\prime}, 5^{\prime}$ monophosphate (cGMP) levels increased when nitric oxide (NO) was administered in the isolated perfused rat lung model (IPRLM); ie, when NO was being administered to the lungs up until their retrieval and freezing. Mean \pm standard error of the mean, $n=6$ per group. ${ }^{*} P<.05$ compared with other groups at the same postmortem time interval. $\# \boldsymbol{P}<.05$ compared with appropriate time $\mathbf{0}$ group.

of ischemic lung tissue in a leukocyte-free environment. Although it can be argued that this is artificial, the foreign surface in the tubing and exposure to air in the reservoir would likely activate platelets and leukocytes. Red blood cells are a source of superoxide dismutase, which could function as a free radical scavenger. By using colloidsupplemented crystalloid as perfusate, any effects on lung weight gain must be related to either endothelial integrity to contain fluid in the vascular space or impaired epithelial clearance of fluid that has leaked into the alveolar space. Eliminating blood components allows the model to focus on the role of pulmonary parenchymal cells in the early phase of reperfusion injury that appears to be important for edema accumulation. In earlier canine lung transplant experiments from NHBDs, increased accumulation of extravascular lung water early after transplantation was associated with an altered A-a gradient. ${ }^{2}$ Therefore it is important to identify strategies that will minimize early capillary leak in lungs retrieved from NHBDs.

Using this model, we demonstrated that agents that increase cyclic adenosine monophosphate (cAMP) levels (isoproterenol) or decrease cyclic adenosine monophosphate breakdown (phosphodiesterase inhibitor rolipram) administered during reperfusion of lungs retrieved from NHBD rats reduced the increase in $\mathrm{Kfc}$ value and edema (W/D ratio). ${ }^{13,14}$ Reperfusion of lungs retrieved from NHBDs with the NO donor NTG resulted in similar mitigation of the expected increase in Kfc values and W/D ratios. ${ }^{8}$ With NTG in the reperfusate, it was possible to measure the Kfc values in nonventilated lungs retrieved 3 hours after death, whereas untreated lungs developed florid pulmonary edema and could not reach an isogravimetric state in the IPRLM.
In lungs retrieved 2 hours postmortem, Kfc values and W/D ratios were markedly elevated in untreated lungs. Inhaled NO during reperfusion or during warm ischemia decreased $\mathrm{Kfc}$ values and W/D ratios. In lungs retrieved 3 hours postmortem, the best results were obtained when NO was administered to the NHBD during both ischemia and reperfusion, with dramatic attenuation of increased $\mathrm{Kfc}$ values. This is an extremely important observation because ventilation of an NHBD with 40 ppm NO is a practical option in the clinical setting while arrangements are made to retrieve the lungs for assessment of transplant suitability.

In lungs retrieved 2 hours postmortem, NO administration had similar effects on $\mathrm{Kfc}$ values and W/D ratios as NTG reperfusion in our earlier study. ${ }^{8}$ However, in lungs retrieved 3 hours postmortem, reperfusion with NTG only modestly improved Kfc values and W/D ratios, whereas administration of NO during 3 hours of ischemia and with reperfusion dramatically reduced both $\mathrm{Kfc}$ values and W/D ratios.

Administration of NO (40 ppm) to canine recipients of lungs retrieved 3 hours postmortem from nonventilated NHBDs was associated with dramatic improvement in oxygenation and pulmonary vascular resistance during 6 hours of posttransplant observation. ${ }^{15}$ The benefit of NO administration was apparent, even if the agent was discontinued after only 1 hour of reperfusion. Murakami and colleagues ${ }^{7}$ also demonstrated a benefit of NO administration in both porcine and rat models of lung transplantation from NHBDs, but the ischemic time was considerably shorter than ours. Luh and associates ${ }^{16}$ demonstrated a benefit of NO administration (20 ppm) before the onset of 2 hours of ischemia and NO administration with reperfusion in an ex vivo model using lungs from minipigs. Using a rabbit ex vivo lung perfusion model, Schutte and coworkers ${ }^{17}$ showed a beneficial effect of NO administration (10 ppm) before the onset of ischemia or with reperfusion on weight gain, and a benefit of NO (10 ppm) or 8-bromo cGMP administration with reperfusion to reduce Kfc values. Aitchison and colleagues ${ }^{18}$ showed a benefit of NO administration in an ex vivo circuit after intervals of warm ischemia, documented by superior performance after transplant by using a porcine model. Our study shows that administration of NO during the period of warm ischemia in the NHBD might be even more beneficial.

NO was initially known as endothelium-dependent relaxing factor, a potent vasodilator and an endogenous stimulator of soluble guanylate cyclase, which produces cGMP. Cyclic GMP regulates 3 classes of effector proteins: cGMP-dependent protein kinases, cGMP-gated ion-channel protein kinases, and phosphodiesterases, mediating protein phosphorylation, cation influx, and cyclic nucleotide catabolism. ${ }^{19}$

$\mathrm{NO}$ is diminished in endothelial cells after ischemia and reperfusion and after hypoxia-reoxygenation. ${ }^{6,20}$ The NO 
pathway plays a pivotal role in the regulation of microcirculation flow and vascular permeability associated with IRI. Exogenous NO donors reverse increased microvascular permeability and reduce pulmonary injury as a consequence of ischemia and reperfusion. ${ }^{21}$ In addition, administration of NO donors or NO itself has been shown to reduce polymorphonuclear leukocytes influx after pulmonary reperfusion. ${ }^{22}$ NO inhibits neutrophil activation, aggregation, and migration $^{23}$ and reduces cytokine-induced adhesion molecule expression. ${ }^{5}$ In addition, NO might inhibit inflammatory cytokine production by lung macrophages. ${ }^{24}$ Thus exogenous NO administration might reduce lung IRI and improve donor lung function through several mechanisms. Despite the potential role of NO to reduce lung IRI, in the clinical setting of human lung transplantation from conventional donors, only modest or no demonstrable benefit has been observed, ${ }^{25}$ although there was a substantial benefit in a porcine model of lung transplantation ${ }^{26}$ and when administered before warm in situ lung ischemia. ${ }^{27}$

In our study, administration of NO during reperfusion was associated with increased tissue levels of cGMP assessed by means of enzyme-linked immunosorbent assay of whole-lung extracts. If $\mathrm{NO}$ was administered to the NHBD during ischemia but not during reperfusion in the IPRLM, we could not demonstrate significant increases in cGMP levels after more than 30 minutes of perfusion, implying that the effect of exogenous NO administration is shortlived vis à vis its effect on guanylate cyclase. cGMP levels were higher in untreated lungs retrieved and perfused 3 hours postmortem. We saw a similar pattern in an earlier study, when cGMP was measured in lungs reperfused with or without NTG. ${ }^{8}$ Perhaps in the lung guanylate cyclase is stimulated by the stress of ischemia.

There were minimal differences in vascular pressures and resistance among almost all groups in our study. This suggests that pulmonary vasodilation is not contributing to the attenuation of IRI due to NO in lungs from NHBDs. Because the IPRLM is asanguineous, the effect of NO we observed is unrelated to inhibition of neutrophil adherence and the subsequent production of capillary wall damage. The effect is apparent relatively immediately with reperfusion and appears to be related to provision of NO to the ischemic graft, consistent with the notion that during ischemia, lung endothelial cells are deficient in NO. ${ }^{20}$ In earlier studies we showed a relationship between total adenine nucleotide levels in lung tissue and lung parenchymal cell viability $^{28}$ and $\mathrm{Kfc}$ values with reperfusion in untreated lungs. ${ }^{13}$ In the current study the beneficial effect of NO ventilation was unrelated to tissue levels of adenine nucleotides (Table 2).

This study shows that a simple therapeutic intervention delivered through the airway to a dead animal can have a profound effect on lung microvascular function assessed 3 hours after death. Ventilation of a cadaver with NO would be easy to perform in the setting of lung retrieval from a human NHBD. Because of the myriad ways in which humans die, variable warm ischemic time, and other factors that might influence lung function, some method of ex vivo evaluation of lungs retrieved from NHBDs will likely be necessary if transplantation of lungs from NHBDs is to be widely applied in the clinical setting. Indeed, ex vivo evaluation was considered essential when one such transplantation was performed by Steen and associates ${ }^{29}$ in Sweden. Such a system of ex vivo perfusion and ventilation would provide another opportunity to treat the graft with $\mathrm{NO}$ ventilation or other maneuvers. Determining practical methods to reduce the effect of reperfusion on the ischemic lung will facilitate the introduction of lung transplantation from NHBDs and has the potential to allow much broader application of lung transplantation to all patients with end-stage lung disease.

We thank Dr Scott A. Schlidt for technical assistance; Dr C. E. Davis, Professor of Biostatistics at UNC, for assistance with statistical analysis; and Margaret A. Cloud for editorial assistance in the preparation of this manuscript.

\section{References}

1. Egan TM, Lambert CJ Jr, Reddick RL, Ulicny KS Jr, Keagy BA, Wilcox BR. A strategy to increase the donor pool: the use of cadaver lungs for transplantation. Ann Thorac Surg. 1991;52:1113-21.

2. Roberts CS, D'Armini AM, Egan TM. Canine double-lung transplantation with cadaver donors. J Thorac Cardiovasc Surg. 1996;112: 577-83

3. Kiser A, Ciriaco P, Hoffman S, Egan T. Lung retrieval from non-heart beating cadavers with the use of a rat lung transplant model. J Thorac Cardiovasc Surg. 2001;122:18-23.

4. Jones DR, Becker RM, Hoffmann SC, Lemasters JJ, Egan TM. When does the lung die? - Kfc, cell viability, and adenine nucleotide changes in the circulation-arrested rat lung. J Appl Physiol. 1997;83:247-52.

5. de Caterina R, Libby P, Peng H-B, Thannickal VJ, Rajavashisth TB, Gimbrone MA Jr, et al. Nitric oxide decreases cytokine-induced endothelial activation: nitric oxide selectively reduces endothelial expression of adhesion molecules and proinflammatory cytokines. J Clin Invest. 1995;96:60-8.

6. Pinsky DJ, Oz MC, Koga S, Taha Z, Broekman MJ, Marcus AJ, et al. Cardiac preservation is enhanced in a heterotopic rat transplant model by supplementing the nitric oxide pathway. J Clin Invest. 1994;93: 2291-7.

7. Murakami S, Bacha EA, Hervé P, Détruit H, Chapelier AR, Dartevelle $\mathrm{PG}$, et al. Inhaled nitric oxide and pentoxifylline in rat lung transplantation from non-heart-beating donors. J Thorac Cardiovasc Surg. 1997; 113:821-9.

8. Egan TM, Hoffmann SC, Sevala M, Sadoff JD, Schlidt SA. Nitroglycerin reperfusion reduces ischemia-reperfusion injury in non-heartbeating donor lungs. J Heart Lung Transplant. 2006;25:110-9.

9. Egan T. Non-heart-beating donors in thoracic transplantation. J Heart Lung Transplant. 2004;23:3-10.

10. de Perrot M, Liu M, Waddell TK, Keshavjee S. Ischemia-reperfusioninduced lung injury. Am J Respir Crit Care Med. 2003;167:490-511.

11. Adkins WK, Taylor AE. Role of xanthine oxidase and neutrophils in ischemia-reperfusion injury in rabbit lung. J Appl Physiol. 1990;69: 2012-8.

12. Seibert AF, Haynes J, Taylor A. Ischemia-reperfusion injury in the isolated rat lung. Am Rev Respir Dis. 1993;147:270-5. 
13. Jones DR, Hoffmann SC, Sellars M, Egan TM. Reduced ischemiareperfusion injury with isoproterenol in non-heart-beating donor lungs. J Surg Res. 1997;69:385-92.

14. Hoffmann S, Bleiweis M, Jones D, Paik H, Ciriaco P, Egan T. Maintenance of cAMP in non-heart beating donor lungs reduces ischemia-reperfusion injury. Am J Respir Crit Care Med. 2001;163:1642-7.

15. Takashima S, Date H, Aoe M, Yamashita M, Andou A, Shimizu N. Short-term inhaled nitric oxide in canine lung transplantation from non-heart-beating donor. Ann Thorac Surg. 2000;70:1679-83.

16. Luh S-P, Tsi C-C, Shau W-Y, Shiau S-YS, Jan I-S, Kuo S-H, et al. Protective effects of inhaled nitric oxide and gabexate mesilate in lung reperfusion injury after transplantation from non-heart-beat donors. J Heart Lung Transplant. 2002;21:251-9.

17. Schutte H, Witzenrath M, Mayer K, Rosseau S, Seeger W, Grimminger F. Short-term "preconditioning" with inhaled nitric oxide protects rabbit lungs against ischemia-reperfusion injury. Transplantation. 2001;72:1363-70.

18. Aitchison JD, Orr HE, Flecknell PA, Kirby JA, Dark JH. Nitric oxide during perfusion improves posttransplantation function of non-heartbeating donor lungs. Transplantation. 2003;75:1960-4.

19. Lohse MJ, Förstermann U, Schmidt HHHW. Pharmacology of NO: cGMP signal transduction. Naunyn Schmiedebergs Arch Pharmacol. 1998;358:111-2.

20. Pinsky D, Oz M, Liao H, Morris S, Brett J, Sciacca R, et al. Restoration of the cAMP second messenger pathway enhances cardiac preservation for transplantation in a heterotopic rat model. $J$ Clin Invest. 1993;92:2994-3002.

21. Abdih H, Kelly CJ, Bouchier-Hayes D, William R, Watson G, Redmond HP, et al. Nitric oxide (endothelium-derived relaxing factor) attenuates revascularization-induced lung injury. $J$ Surg Res. 1994;57:39-43.

22. Yamashita M, Schmidt RA, Ando K, Cooper JD, Patterson GA. Nitroprusside ameliorates lung allograft reperfusion injury. Ann Thorac Surg. 1996;62:791-7.

23. Kubes P, Granger DN. Nitric oxide modulates microvascular permeability. Am J Physiol. 1992;262:H611-5.

24. Meldrum DR, Shames BD, Meng X, Fullerton DA, McIntyre RC Jr, Grover FL, et al. Nitric oxide downregulates lung macrophage inflammatory cytokine production. Ann Thorac Surg. 1998;66:313-7.

25. Meade MO, Granton JT, Matte-Martyn A, McRae K, Weaver B, Cripps $\mathrm{P}$, et al. A randomized trial of inhaled nitric oxide to prevent ischemia-reperfusion injury after lung transplantation. Am J Respir Crit Care Med. 2003;167:1483-9.

26. Bacha EA, Hervé P, Murakami S, Chapelier A, Mazmanian G-M, de Montpreville V, et al. Lasting beneficial effect of short-term inhaled nitric oxide on graft function after lung transplantation. J Thorac Cardiovasc Surg. 1996;112:590-8.

27. Waldow T, Alexiou K, Witt W, Wagner FM, Gulielmos V, Matschke $\mathrm{K}$, et al. Attenuation of reperfusion-induced systemic inflammation by preconditioning with nitric oxide in an in situ porcine model of normothermic lung ischemia. Chest. 2004;125:2253-9.

28. D'Armini AM, Tom EJ, Roberts CS, Henke DC, Lemasters JJ, Egan TM. When does the lung die? Time course of high energy phosphate depletion and relationship to lung viability after "death." J Surg Res. 1995;59:468-74.

29. Steen S, Sjoberg T, Pierre L, Liao Q, Eriksson L, Algotsson L. Transplantation of lungs from a non-heart beating donor. Lancet. 2001;357:825-9.

\section{JTCVS On-Line Manuscript Submission and Review}

The Journal of Thoracic and Cardiovascular Surgery requires authors and reviewers to submit all new and revised manuscripts and reviews via Editorial Manager. Point your browser to http://jtcvs.editorialmanager.com, log in as author or reviewer (as appropriate), and follow the instructions provided.

To retrieve your username and password, click "Forget your password?" on the Editorial Manager log-in page.

If you have questions or experience problems uploading your manuscript or review, please contact the editorial office:

Telephone: 215-762-1854

E-mail: jtcvs@drexel.edu 